\title{
Inheritance and reflection: "re-study" of three anthropology fieldwork sites in China's Yunnan Province
}

\author{
Mingming Wang ${ }^{1}$
}

Received: 26 June 2021 / Accepted: 13 July 2021 / Published online: 04 August 2021

(c) The Author(s). 2021

\begin{abstract}
This article is a research report involving three anthropological studies conducted during the period of "Kuige" and their "re-studies." By narrating the project, I set forth my views on the connections and differences between Chinese anthropological explorations from two historical periods. These anthropological explorations refer to the study of Lu Village conducted by Fei Xiaotong, that of "West Town" (Xizhou) by Francis L. K. Hsu, and that of "Pai-IPai" (Dai) villages by Tien Ju-Kang. They were all completed in the late 1930s and early 1940s. Each writer extracted a framework to analyze the land system, ancestor worship, and the relationship between humans and gods from the writer's own field experience. Despite the difference in research methods, all three studies noticed the cultural differences between rural society and modernity. Since 2000, Peking University and Yunnan Minzu University have launched a "Province-university Cooperation Project." During the project, a research team formed of several young scholars revisited Lu Village, "West Town" (Xizhou), and Namu Village. These writers' works were based on the data acquired in their fieldwork and drew upon the opinions raised by global anthropologists on "re-study" in recent decades. Considering the dual effects of social change and shifts in academic concepts around "follow-up research," the scholars put forward several points of view with their ethnographies, which all featured the characteristics of inheritance and reflection. Based on the results of the three "re-studies," this article emphasizes the importance of the study of public rituals for the research of rural society. This article also attempts to re-examine the methodology of "human ecology," which profoundly impacts Chinese anthropology and sociology.
\end{abstract}

Mingming Wang

ming_mingwang@163.com

1 Department of Sociology/Institute of Sociology and Anthropology, Peking University, No.5 Yiheyuan Road Haidian District, Beijing 100871, China 
Keywords Kuige · Re-study · Exchange • Public rituals • Human ecology · Anthropology

\section{Introduction}

In the 1930s and 1940s, Yunnan became one of the main anthropological fieldwork sites in China. In the early 1930s, Mr. Yang Chengzhi of Sun Yat-sen University was already conducting some research in physical anthropology and ethnology in central and western Yunnan. Following his example was Jiang Yingliang, an anthropologist who also went to Yunnan to investigate the Dai ethnic group. In 1938, while the whole country struggled to fight off the Japanese invasion, many scholars, mostly working for academic institutions such as Southwest Associated University, West China University, and Yunnan University, gathered in Southwest China to do their part. Their joint efforts enabled unprecedented progress in the teaching and research of disciplines such as liberal arts, science, engineering, medicine, and agriculture, including in the research and development of anthropology, sociology, and border politics, among other disciplines. Several aspirant scholars emerged in these disciplines, who endeavored to conquer all the difficulties in their way, proceeding to make outstanding contributions that benefited the generations to come and left a valuable legacy for Chinese academia.

At the turn of the twenty-first century, as part of a "Province-institution/university Cooperation" project granted by the Yunnan provincial government, Yunnan Minzu Institute (now renamed as "Yunnan Minzu University") and Peking University joined hands to set up a cooperation project for a "key discipline." To build upon the academic heritage of the "Southwest Associated University period," we, as investigators on this cooperation project, proposed in September 2000 to restudy the well-known anthropological fieldwork sites in Yunnan. Upon approval, I picked a few fieldwork sites and organized some doctoral students majoring in social anthropology to participate in the follow-up field study. During the design and implementation of this project, we paid particular attention to Fei Xiaotong's research of the "Three Villages in Yunnan," Francis L. K. Hsu's study of ancestor worship in the West Town (Xizhou) of Dali, and Tien Ju-Kang's study of the "PaiIPai" (Dai) villages. ${ }^{1}$ It was under the rigorous requirements of ethnographic methods that the Chinese social anthropology researchers completed these studies during the War of Resistance against Japanese Aggression (1937-1945). All three older-generation anthropologists mentioned above were members of the "Kuige" Sociological Workstation in Chenggong county of Yunnan Province, who are addressed respectfully as the "Kuige school" by later researchers. Their related achievements are also seen as representative works for the "Kuige Period" in the history of Chinese social anthropology.

\footnotetext{
${ }^{1}$ Wang Jianmin did a relatively comprehensive introduction of the overall research and development of Chinese anthropology in this period in his book History of Chinese Ethnology (Volume I) (1997: p229242; p291-297).
} 
The "Kuige school" represents the distinctive academic achievements made in Chinese sociology and anthropology during a specific period. In 1938, after completing his doctoral dissertation, Fei Xiaotong, with 50 British pounds given to him by his supervisor Malinowski, arrived in Vietnam by sea. He then took a route through Vietnam into China's Yunnan Province, a "haven" during the War of Resistance against Japanese Aggression. Upon his arrival, instead of looking for a job in Yunnan, Fei Xiaotong took advantage of a relative's missionary connections in Lufeng County to enter the area. He chose Lu Village as a fieldwork site, planning to use the community as a starting point for a series of "type comparison" studies. From 1939 to the early 1940s, Fei was the director of the Sociology Research Office jointly established by Peking University and Yunnan University. To avoid bombings by Japanese warplanes, the Office was relocated to the "Kui Xing Ge" (or "Kuige") in Chenggong county in 1940. Since then, Fei Xiaotong convened social surveys and academic seminars that engaged anthropologists and sociologists. Aside from Fei Xiaotong himself, those who worked on social anthropology were Zhang Zhiyi, Francis L. K. Hsu, Tien Ju-Kang, Li Youyi, Hu Qingjun, and others (Fei 1993; Zhang 2000; Pan 2001; Wang 2004). These scholars each made their contributions to the subsequent development of Chinese social sciences.

I had previously encountered these works of social anthropology research from "Kuige" in two different ways. More than a decade ago, I dabbled in several classics for Chinese social anthropology written by members of the "Kuige," including the aforementioned Fei Xiaotong et al.'s Three Villages in Yunnan (1990 [1951]), Francis L. K. Hsu's Under the Ancestors' Shadow (1948), and Tien Ju-Kang's Religious Cults of the Pai-I along the Burma-Yunnan Border (1946). Later, when I studied in London, Professor Stephan Feuchtwang, a student of the famous Sinological anthropologist Maurice Freedman, told me that when he was working on his Ph.D., these three books were required readings by Freedman in addition to Fei Xiaotong's Peasant Life in China and Lin Yaohua's The Golden Wing. ${ }^{2}$ Later, I also read in Freedman's own treatises that the formulation of his theory was indeed closely related to his reflections on these three books. ${ }^{3}$ To figure out the limitations of ethnographic research in China under the framework of Freedman's work, I spent time on these early social anthropological works, which gave me the first taste of their unique appeal and intrigued me to visit the places described in these works.

My "indirect experience" with the social anthropology of the "Kuige" when I was studying abroad was later connected with a research trip to China. It was around 1998 when Professor Pan Naigu of Peking University handed me a copy of a manuscript and said in her familiar, soft voice, "There is something interesting about this one." The article, written by a writer Xie Yong and entitled Kuige: The Prototype of a Modern Chinese Academic Group, was about a unique era of

\footnotetext{
${ }^{2}$ Nonetheless, it is important to note that while proclaiming the importance of these local studies, Freedman, based on the concept of "Social Structure," has argued against "Type Comparison" used in the survey of small local communities (Freedman 1963).

${ }^{3}$ As I have mentioned in other papers, Freedman made an important contribution to Chinese anthropology by pointing out that the discipline should not be satisfied with village studies but should expand its horizons to the entire social fabric of China (Wang 1997a, b).
} 
Chinese sociology and anthropology during the Southwest Associated University period, from 1937 to 1945 . The author passionately states that the small group of intellectuals led by Mr. Fei Xiaotong during that period had demonstrated the possibility of "teamwork" in modern Chinese academia (Xie 1998). Xie later wrote an article lamenting the difficulty of fully reviving the model created by Chinese intellectuals in the "bygone era." Professor Pan Naigu asked me to read Xie's article, probably because she thought that the down-to-earth academic working style and "team spirit" of the "Kuige" period were traits worth passing on in the construction of the social anthropology discipline in China today. As I had paid little attention to "team spirit," her words struck me as a reminder that the concept of "Kuige" and all that it represents could be invaluable for China's new generation of researchers to learn something new from the academic paths of their predecessors.

The "province-university cooperation project" between Peking University and Yunnan Minzu University, launched at the beginning of the twenty-first century, provided an excellent opportunity for us to revisit the old fieldwork sites and see if we could learn anything new from them. By mid-2003, we had gradually completed the re-investigation of the three studies. ${ }^{4}$ Zhang Hongming, Liang Yongjia, and Chu Jianfang, the doctoral students from Peking University, implemented the re-investigation and completed three successive reports submitted as their Ph.D. dissertations for defense. ${ }^{5}$ The three doctoral dissertations each had their own thematic strengths and built upon the established ethnography of three previous social anthropologists. They focused on the land system (Zhang 2002), territorial cults (Liang 2003), and "exchange between people and gods" (Chu 2003), respectively, reflecting on their inheritance and articulating their own understanding of the implications and limitations of the arguments put forward by the anthropologists 60 years ago. As the co-PI of the project, I have collaborated with the three Ph.D. students in their reflections over the years. I have also visited the communities they studied for short periods. Based on the three doctoral dissertations' main findings and my impressions, this article seeks to raise questions left by these dissertations for further analysis and discussions. This article is written in the format of a report and will outline the following three areas in turn:

1) The author's understanding of the ideas used to develop the subject and the significance of the subject;

\footnotetext{
${ }^{4}$ Professor He Shaoying and Professor Luo Hailin of Yunnan Minzu University have been of great help to our "Restudy" project by offering much-needed guidance and arranging for the researchers to visit the fieldwork sites. Professor Pan Naigu of Peking University, one of the project's PIs, also visited the fieldwork sites and gave the project members guidance.

${ }^{5}$ After passing their dissertation defense, they each received doctoral degrees between 2002 and 2003. Before that, the three of them were Ph.D. students in social anthropology at the Institute of Sociology and Anthropology, Peking University, under the joint supervision of Professor Fei Xiaotong and myself. The three doctoral dissertations were designed based on the outline of "Construction of Key Disciplines in Ethnology," a "Province-university Cooperation Project" between Peking University and Yunnan Minzu College (now renamed as "Yunnan Minzu University"). As a sub-project (jointly undertaken by Prof. Pan Naigu and me), it was entitled "Restudy of Famous Anthropology Fieldwork Sites in Yunnan" at the time of application.
} 
2) The process of each study, and the academic merits, especially in the study of the relationship between land, rituals, and exchange;

3) A discussion on "human ecology," which is closely related to the subject matter while taking the significance of "historical anthropology" into account.

\section{Methods: from follow-up study to re-study}

This project research falls in the scope of "follow-up study." There have been considerable differences in the practices of "follow-up study" domestically and overseas. Domestic scholars are more focused on comparing what happened before and what is happening now on the same fieldwork site, especially regarding social changes and development. On the other hand, foreign scholars have their eyes on what influence different thinking methods may have on the perception of the same fieldwork site (Zhang 2002). A study at an old fieldwork site is called a "follow-up study" in China, whereas in overseas anthropology, it is called a "re-study." The concept of "follow-up" is easy to understand. Fei's "revisits" to Hualan Yao, Jiang Village, and three villages in Yunnan are great examples (Fei 1998), and the recently published follow-up studies on villages once conducted by predecessors like Lin Yaohua (Zhuang 2000) are also well known. What is a "re-study"? It is rarely talked about in China. In overseas anthropology, some of the most famous examples under this category include Derek Freeman's "re-study" of Margaret Mead's study on Samoa (Freeman 1990) and Marshall Sahlins and Gananath Obeyesekere's "re-studies" of each other's statements in their battle over the cultural contact events between Hawaiians and the British colonial fleet (Sahlins 2003). Unlike the Chinese "follow-up study," "re-studies" in overseas anthropology are generally based on scholars' change of thinking. For example, Freeman's "re-study" of Mead's fieldwork site is based on the change of thinking on the relationship between human nature and culture, while the debate between Sahlins and Obeyesekere over the history of the relationship between indigenous perspective and imperialism is closely related to their different "indigenous perspectives."

How do we properly position our project when there is no consensus between domestic and overseas anthropologists on the concept of "follow-up studies"? It is a question that has been constantly brought up during the implementation of the project. ${ }^{6}$ Mr. Fei Xiaotong used to mentor the three doctoral students in person,

\footnotetext{
${ }^{6}$ One of my colleagues who knew I was going to co-investigate the "follow-up study" project once mentioned a "phenomenon" to me, slamming that "Now, quite a few anthropologists in China pick those famous fieldwork sites to conduct follow-up studies just because it is easier for them to get famous." It is undeniable that this phenomenon does exist, but the purpose of our project team's follow-up studies was by no means to pander to this trend. In my opinion, first and foremost, the "follow-up studies" should show respect to predecessors' academic achievements. Through the accumulation of more than 100 years' work by social anthropologists, most of the regions and peoples of the world have been covered by ethnographers, which means that every new study could be regarded as a "follow-up" of previous studies in a certain way. To claim the "originality" of their studies, a few scholars may refer to their follow-up of certain established sites as "first discovery." However, most social anthropologists are aware that it will be difficult for them to create anything new without connecting their research with the academic history of regional studies.
} 
and during his teaching, he recalled "Kuige" many times, which has led to a widespread view of research methods. In July 2003, Fei repeatedly mentioned two academic paths to a "follow-up study." "A follow-up study is reflecting changes in the society that we are studying, or in our theories and mind. Either way is fine," he said. ${ }^{7}$ That is to say, "follow-up study" and "re-study" each have their own advantages, and for the new generation scholars who are revisiting the old fieldwork sites, they can choose one of them or just use both. By my understanding, Fei's remarks also urge us to avoid the simplistic tendency to "follow-up study" or "restudy" and look dialectically at the relationship between inheritance and reflection on the achievements of predecessors.

In practice, discerning this new, comprehensive "follow-up study" is not straightforward. The sites have already been picked and studied by predecessors in the past, and the study subjects had also been defined by the fieldwork "initiator" 60 years ago. ${ }^{8}$ So how can we incorporate both inheritance and development into our study? From my perspective, our predecessors' ethnographic research for the three social anthropological fieldwork sites that we have selected is quite solid. This fact cannot be ignored by the new generation scholars in their "follow-up studies." Therefore, I believe, while opting not to repeat the simplistic approach to "follow-up studies," the project members must be more prudent with the predecessors' achievements by avoiding the extreme relativization of theoretical interpretation as some anthropologists have done, overthrowing the predecessors' interpretation and exposing their shortcomings. However, lingering on the repeated argumentation of "past" and "present" is undoubtedly not a solution either. The right way may be to take an approach to "re-study" that emphasizes academic reflection, which means putting more effort towards collecting materials and, meanwhile, doing anything possible to make a difference in theorizing. To clarify the meaning of this dual-purpose more clearly, we can define the overall goal of the project as "reflective inheritance." What is "reflective inheritance"? Rather than being a theory, it reflects only an academic attitude that the researchers should develop academic autonomy in studies, possessing an awareness of both the achievements and limitations of their predecessors, that is, "knowing why and how they do it, and what his focuses are." While realizing the value of previous research, it is time for them to contribute to the accumulation of academic knowledge (Liang 2003). It is true that "reflective inheritance" can hardly satisfy the requirements of today's prevailing critical social sciences and "postmodernism" (the latter tends to advocate comprehensive reflection). However, it is of great significance to urging researchers to research in a down-to-earth manner. Moreover, it is of unique value for the development of social anthropology as a discipline with a relatively weak foundation in China.

Sixty years have passed since the "Kuige" period of social anthropology studies. During this time, significant changes have taken place in Chinese society.

\footnotetext{
${ }^{7}$ Transcript of records.

${ }^{8}$ It is worth reiterating that the land system of Lu Village studied by Zhang Hongming, the rituals of Xizhou Town studied by Liang Yongjia, and the "Pai" of Mangshi studied by Chu Jianfang were the focal points of Fei Xiaotong, Francis L. K. Hsu, and Tien Ju-Kang respectively.
} 
Following up at selected fieldwork sites allows us to see a whole picture of the old conditions and new community changes being studied. Simultaneously, the implementation of follow-up studies for old anthropological fieldwork sites also provides an excellent space for theoretical thinking at the beginning of a new century. By revisiting these places, we trace the timeline for the development of social anthropology, which enables us to inherit and carry forward our predecessors' academic careers, think of broader disciplinary issues, and come up with our interpretation. In this way, the goal of "reflecting the changes in theory and mentality of our researchers," as quoted from Mr. Fei Xiaotong, has been achieved. During the research, the project members always put fieldwork first and consider social anthropology questions based on solid participant observation. In doing so, they separately carried out about half a year's fieldwork. Though shorter than the requirement of "a full year" for traditional social anthropology, they have done all they could for now. During their preparation for the fieldwork and collection of data, they browsed a variety of literature around their respective topic, especially theoretical discussions about land, rituals, and exchange, and the relationships between the three. Based on these previous discussions and some previous debates in China and abroad, they put forward their respective narrative frameworks of ethnography, which have achieved relatively good results.

\section{Results and discussion}

\section{Lu Village: land and rituals}

The first fieldwork of the Co-PI project was conducted at Lu Village, where Fei Xiaotong and Zhang Zhiyi had studied. The village, located in Lufeng County, is the subject of analysis in the book Farmland of Lu Village., ${ }^{9}$ jointly completed by Fei and Zhang. The book, in a way, set the stage for other social anthropological studies in the "Kuige" period.

Over 60 years ago, the remote Lu Village, located in the southwest corner of China, was a "rural area isolated from the modern industrial and commercial cities." When Fei Xiaotong first set foot in Lu Village, he was concerned about the following matters:

What does the land system look like in a rural area that is little influenced by modern industry and commerce? As a rural area still mostly self-sufficient, will it attract large amounts of the township and municipal funds with land rights? Moreover, will rural land rights be concentrated in towns and cities, resulting in big landlords moving away from the land? (Fei et al. 1990)

Fei Xiaotong had already noticed the importance of land rights in Peasant Life in China. While land rights in Jiang Village tend to accrue to towns and cities, the

\footnotetext{
9"Farmland of Lu Village," together with "Handicraft of Yi Village" and "Agriculture and Commerce of Yu Village" by Zhang Zhiyi, was published by University of Chicago Press in 1945 under the name of Earth-bound China: A Study of Rural Economy in Yunnan; In 1990, it was published in Chinese by Tianjin People's Publishing House under the name of Three Villages in Yunnan(云南三村)
} 
land rights in Lu Village remain intact locally. Moreover, one distinctive feature of the land system in Lu Village is that landowners generally do not cultivate their land. Instead, they lease the land to hired laborers from outside the village for farming and make a living out of it. The accumulation of agricultural capital relies on the difference between farmland production and the livelihoods of farmers. Unlike Jiang Village, where industry and commerce are developed, Lu Village has a plentiful labor supply, but capital is still not easy to accumulate there. The local people expect to raise and accumulate capital through "promotion and getting rich" instead of "hard work." Therefore, unlike the Jiang villagers who are busy working and deeply influenced by modern industry, the people in Lu Village have much free time, which they usually spend enjoying a surplus in local public rituals. The economy can be differentiated between "private use," rationally calculated, and "public use," mostly for public entertainment. This sort of mixed-use creates a "production-leisure economy." In short, for Fei Xiaotong, the "production-leisure economy" in Lu Village represents the small-scale peasant economy before the development of modern industry and commerce, which is quite different from the capitalist "production-consumption economy."

In the 1930s and 1940s, $27 \%$ of the land in Lu Village was under local "common ownership" at varying degrees. Some were held collectively by the whole village, and some by a limited group of people related to the "public rituals" (clan land or temple land). Regarding the origin of this joint ownership by a group of people, Fei Xiaotong explained it from the functionalist perspective. In his view, the land under "common ownership" belongs to various folk cultural organizations that provide peasants with "entertainment activities," including ancestor rituals, Dongjing Association (a mass music organization worshiping Taoism in Yunnan ethnic minority areas), and temple festivals. How can we understand this society, with its large amounts of "communal" land and the mechanisms through which it operates? Fei Xiaotong emphasizes that "aversion to labor is a common attitude in Lu Village" (Fei et al. 1990). Unlike the Jiang villagers, the peasants in Lu Village are averse to labor, and modern concepts of industry and commerce do not influence them. Their perception of happiness is entirely different from that of the capitalist society, where the pursuit of more happiness is built upon increasing labor sufferings. In peasant societies like Lu Village, people are reluctant to endure such suffering, so they have little desire to pursue happiness, which in turn makes them "tend to reduce consumption to reduce toil" (Fei et al. 1990). The existence of a large amount of communal land in Lu Village has something to do with the villagers' reduction of their desires, which are replaced by "leisure activities" relating to folk culture (in fact, "folk rituals").

Fei Xiaotong's views on peasant economic perceptions in his study of the Lu Village are pretty meaningful. As part of Three Villages in Yunnan, Lu Village provides a typology for Fei's "type comparison," which parallels the other two types of economic lifestyles (small-scale handicrafts and commodity economy) in rural China. They constitute three consecutive transitional forms in time. In the process of the "type comparison," Fei views the Lu Village as a typical small-scale peasant economy. He distinguishes this economy from industrial and commercial capitalism based on the degree of desire and examines the "communal" part of the 
economy in Lu Village as a social mechanism for "desire reduction." His approach of "seeing the big picture from small details" is a model for social anthropology research, and therefore worth rethinking for us, half a century later.

Zhang Hongming, who was assigned to conduct the re-study in Lu Village, analyzed the "leisure economy" proposed by Fei Xiaotong during his research. In the summer of 2001, I went to Lu Village with him and found that it was indeed one of the thousands of ordinary Chinese villages. However, we heard that overseas anthropologists had also visited the village during these years in addition to domestic scholars. Among them, Laurel Bossen, an American scholar, had been to Lu Village for long-term fieldwork, with a focus on the relations between women and development, especially "how Chinese culture, communist planning, and marketdriven reforms shape and are shaped by gender definitions and relations in everyday practice" (Bossen 2002). In Bossen's later published work, the study of $\mathrm{Lu}$ Village from a gender perspective supplements Fei's original "gender-neutral" approach to community research. However, she did not pay sufficient attention to the "leisure economy" proposed by Fei. After our initial visit, Zhang Hongming and I concluded that the issue of rural China still lies in the land, and therefore, our "restudy" of Lu Village must continue to focus on its land system.

Zhang Hongming's fieldwork also deals with the social changes in Lu Village over the past 60 years. However, he focuses more on what Fei Xiaotong mentioned as the latter type of research. He re-examines the issue of land rights that Fei had been concerned about, based on "the changes in researcher's theories and mentality." It is worth mentioning that although the old works of Fei Xiaotong and Zhang Zhiyi have described the landscape of the land system in Lu Village, they did not lay out the historical background of the formation of this system due to a lack of historical concerns in their fieldwork. When Fei was engaged in fieldwork at $\mathrm{Lu}$ Village, the study of rural society had just started, and for social anthropology at that time, the rural society was studied as one of the remote ethnic minority groups. It was not until later that anthropologists became keenly aware that the rural society was not only a predecessor of civilizational society but also an integral part of a "complex society" with a "state and history." In light of this change in research rationale, Fei has reviewed the community survey method and the concept of "earthbound China" that he had adhered to, acknowledging that his community survey in the early days could not reflect the overall Chinese social structure and stating that Chinese anthropology needs to embrace an era of "civilizational society research" to find a theoretical basis (Fei 1998). Influenced by Fei's reflective philosophy, Zhang Hongming employs a historical-anthropological method to broaden his horizons by conducting fieldwork from a historical perspective. He expands the temporal scope of the study to pre-Republican history to examine the changes in farmland ownership in Lu Village from a more historical perspective.

After 6 months of fieldwork, Zhang Hongming was keenly aware that, unlike what is described in Farmland of Lu Village, the land in Lu Village only superficially belongs to the villagers. For a long time, the land here had always been "allocated" to peasants by the emperor, which means that the imperial state was the owner, while the peasants were only land users. They were under pressure to pay taxes every year, and the imperial court would spend the tax money in the form of 
a "redistribution" system for "public" affairs such as "rituals." In other words, the role of the "redistribution" system has always been central to rural land ownership. Zhang Hongming's doctoral thesis, which was defended and passed in June 2002, traces the evolution of the relations between the ancient national land system and modern land issues. The thesis states that the so-called "leisure economy" is a civil institutional arrangement of local public rituals.

This assertion reminds me of the dialectical relations between "public" and "private" in rural society, which I have repeatedly emphasized many years ago in a case study of Xi Village in Fujian province. Our impression of the peasants has always been that they are a group of people who need to be instilled with "public awareness" and given "citizenship." The study of Xi Village shows that peasants have developed a hierarchical view of "public and private" ownership over a long time and that public ownership prevails in their lives. To maintain the collective rituals central to public life, the Xi villagers have invested much time, effort, and material resources in building and renovating village temples, ancestral halls, and ancestral tombs. Moreover, these spaces, which our modern political economists regard as a "waste of economy," are the public spaces of local society (Wang 1998).

In the study of Lu Village, once again, I found the social value of the "economy of wasting." There has been an orthodox "civilizing" movement in Yunnan since the Ming Dynasty, and the so-called "Dongjing Culture" may be the core of such a movement. The Lu villagers do not cultivate the land, and they spend much time on temple festivals and Dongjing music as if they were the messengers of "elite culture" in local society. They distinguish themselves from migrant workers by positioning their cultural identity as "internal" and thus distinguishing themselves from what they consider to be "external" workers. Their perception of the "private" and "public" is based on the distinction between the work of migrant workers and the "leisure" of local villagers. The "Dongjing Association" and temple festivals, which are particularly important in the "leisure economy," are generally not attended by migrant workers or cultivators. In this way, the Lu villagers establish themselves as “insiders of the mainstream culture (化内之民)," while the migrant workers, as outsiders (化外之民) to their community, do not own land and do not have the right to participate in local "public social activities."

How can we explain the historical formation of this important distinction between insiders - those who own land, and outsiders - those who do not own land? To answer this question, we should still pay further attention to the systems related to "redistribution." Historically, land ownership had always been part of the "household registration" system. The migrant workers in Lu Village were not registered because they were "displaced persons." Moreover, without a registered household, they could not own land in the "system," so the locals bore the taxes with registered household and land, and the surplus went to them as well. It is obviously the surplus part that the Lu villagers spent most on what Fei Xiaotong called "leisure." This shows that the peasants" "leisure economy" is closely related to the state's "redistribution" of land. When emphasizing "redistribution," however, it seems important not to lose sight of the fact that the long-established ideal of "land to the tiller" may have an "unintended consequence": namely, peasants have long retained the right to locally reorganize the land they have been "redistributed" 
from the state. The "leisure" of Lu villagers is one form of such "local reorganization." Studies have shown that "leisure" is related to the maintenance of local public "self-image." It is worth reiterating that the Lu villagers mirrored the forms of public activities provided by the imperial court through "indoctrination" to identify themselves as "insiders of the mainstream culture" and thereby distinguished themselves from the migrant workers. Therefore, their "leisure economy" featured a noteworthy duality: on the one hand, its existence was "socially rational," helping to create and maintain the "boundary" of the local community; on the other hand, while creating and maintaining such a "boundary" that distinguished between the insiders and outsiders, the "leisure economy" closely integrated the top-down "indoctrination" process with the sense of locale.

From the study of land use to the historical "civilizing process (教化), " we get the impression that the re-study of Lu Village has gone too far in terms of its focus. The land system, or what Fei Xiaotong calls "the set of social relations that occurred from the use of farmland" (1990), is the domain of economic anthropology, while the evolutionary history of the "civilizing process" and the community's "sense of place" is mostly of interest to cultural historians only. This cross-field association, however, is not without reason. The points mentioned above suggests a correlation between the facts that have generally been classified in two fields. How do we understand this correlation? I think that historical inspiration is still essential. Historically, in the process of "appeasement" of "frontier areas" such as Yunnan, the imperial court usually distributed the "colonized" land to the "frontier" migrants (including "military households"). To incorporate the mobile population in the frontier areas into the settled society, the imperial court usually adopted the method of "household registration" to stabilize them and turn them from "displaced persons" to "residents." Household registration is central to this process (which has not received sufficient attention in Zhang Hongming's argument). The household registration is a way to confirm the number of "people" and regulate the inhabitants of the frontier areas far from the emperor. In the process of household registration, inhabitants have established a double relationship with the state. One is about "redistribution," which Zhang Hongming has focused on, and the other is about public rituals that contribute to the "leisure economy." Furthermore, it is worth noting that the public rituals that historically took place in villages may have temporarily been part of the cultural model designed by the imperial court in an era such as the early Ming Dynasty. However, throughout history, this may have tended to be "off track," changing "ritualism" to the so-called "overbuilding of temples" (Wang 2003).

In other words, the "economic types" (including the "leisure economy") that have been identified as spontaneously emerging from the peasants are inseparable from the overall system and culture that have played an integral role in "Chinese history." If we want to compare traditional China with "capitalism," the "leisure economy" in Lu Village hardly constitutes a "type" by which we can distinguish between the two of them. It is not that the study of this trivial part of the social system is not important, but that to compare this with the "capitalism" that affects the whole world would make us vulnerable to the risk of neglecting its relations with the "redistribution" system of the ancient civilization, as well as the 
"economic type" of modern "capitalism," which falls into the category of "postredistribution."

When the Lu Village farmland became an object of study in rural anthropology, rural China was already in the middle of significant change. In that era, to find an explanatory framework for social change, intellectuals, on the one hand, explored the "matrix" of rural society and, on the other, tried their best to understand the difference between "traditional" and "modern." In the "type comparison" proposed by Fei Xiaotong, the Lu Village is a typical "matrix" of rural China, and its "leisure economy," which is closely related to land ownership, has become the basis for scholars to explain the difference in cultural typology between "peasants" and "capitalists," "traditional" and "modern." It has also become a means for scholars to predict the "future" based on the "past." Revisiting the discovered typologies over half a century later, we realize that a community survey focusing on typologies and comparisons needs to be complemented by a broad cultural-historical perspective. Only in this way can we understand the historical positioning of the classified and compared communities, the interaction process between "orthodox" and "folk" in local societies and the significant influence of this interaction on the process of establishing local "economic typologies." Therefore, rural studies can genuinely approach the study of "civilizational societies" to understand China as a whole.

\section{Xizhou: territorial cults and the composite structure}

The "re-study" of Lu Village has paved the way for the other two studies that followed, making them more focused on rituals and cultural issues.

The second "re-study" site selected by the research team is Xizhou, Dali (大理 喜洲). Compared with the ordinary Lu Village, Xizhou has a rich culture. With the Cang Mountains to the west and the Erhai Lake to the east, this large village was once one of the central places in the cultural development of the Dali region. Today, when we visit the village, we see a rural community built as a "township." In mid-May 2002, after a visit to Mangshi, I went to Xizhou with Liang Yongjia, who was conducting fieldwork in Xizhou. I found that the houses of ordinary villagers and "big families" were protected as "cultural heritage," attracting many tourists. Standing at the village center, the Square Street, I could imagine how the Pai civilization, which developed independently for a long time before the Yuan Dynasty, experienced the conquest by the "late Empire" and transformed from civilization into the "minority" during the civilizing process of the Ming and Qing Dynasties, as well as the longing of the "minority" as the historical legacy for the mainstream culture. In social anthropology, this place is widely known by the name "West Town (西镇)." Francis L. K. Hsu, a former member of the sociological workstation of the "Kuige," came to Xizhou in 1941, where he did 14 months of fieldwork, and in 1948 he wrote Under the Ancestors' Shadow (book title named by Fei Xiaotong), which describes the family and ancestral rituals of the people in this area. The cultural elements described in the book are probably the results of the "Sinicization" of the Dali region after the Ming Dynasty. This place was also closely studied in the Social-historical Surveys of China's Ethnic 
Minorities since the 1950s. At that time, to demonstrate the uniqueness of the Pai culture, ethnographers chose "the worship of the benzhu (本主)," a "primitive" belief of the village communities in the Dali area, as the central object of observation, which is different from the family and "ancestors' shadow" described by Francis L. K. Hsu. They tried to trace the history of Dali before the Yuan and Ming dynasties, which they identified as the main symbol of the indigenous Pai culture (Liang 2003).

While guiding the fieldwork and data analysis of Liang Yongjia, I have been focusing on the worship of the benzhu in Xizhou. This is because of a friend in anthropology who knows that I am particularly interested in the study of territorial cults (Wang 2003). When he visited Xizhou and saw the temples and rituals related to benzhu worship, he told me that I should compare this system with the territorial cult system I had studied in southern Fujian. In 2000, while I was a visiting professor in the Department of Anthropology at the University of Chicago, an old friend of Francis L. K. Hsu mentioned West Town. During my lecture, I suggested that a doctoral student interested in Yunnan take a closer look at the history of "non-familial" territorial organization in West Town. That student did later go to Yunnan. I do not know if he took me up on my offer, but the idea of going there has always been in my mind. When I came to Xizhou, the actual name of West Town, I was excited to learn that Xizhou, which was described as a village by the older generation of anthropologists, was once the most ancient city in the Erhai Lake area. Its "demise" from a city to a village fits my interpretation of the "prosperity bygone" in my imagination. ${ }^{10}$

I suggest that Liang Yongjia should focus more on the survey of the worship of the benzhu and compare the cases with the territorial cults of the Han Chinese analyzed by P. Steven Sangren (Sangren 1987) in order to infer the construction of local order and its cultural influence over "ethnic minority areas" since the Ming Dynasty. Liang Yongjia's "tie" with Xizhou has long existed. Before coming to Peking University for his doctoral studies, Liang began fieldwork under the influence of an overseas friend and became interested in the Xizhou family system. I followed Liang's research on Xizhou very closely and offered many suggestions. When it comes to a study of a place, anthropologists generally fall into two schools, one focusing on sorting through the vertical relationships within a place and the other on the examination of horizontal relationships within and outside the place. Most of the early studies of villages adopted the first strategy, and Francis L. K. Hsu is no exception. In his book, he focuses on the continuous ancestral rituals in Xizhou. Although Xizhou people may have gradually learned ancestral rituals from Han Chinese "rituals" after the Ming Dynasty, the "ancestor worship" in Xizhou described by Francis L. K. Hsu seems to represent thousands of years of Chinese culture. He argues that the family organization here, based on the "vertical/horizontal" relations, and the incense that connects people to their ancestors,

\footnotetext{
${ }^{10}$ Through the study of Quanzhou's history, I once tried to point out that some places may have gradually risen to prosperity, as is the "rule" in the general historical narrative (Wang 1999). However, this is not a comprehensive rule because many places have receded from prosperity to adversity. I am afraid that this is also the case in Xizhou.
} 
are socially and logically complementary, reflecting the continuity of Chinese culture. Since the 1950s, Xizhou has been studied as one of the typical examples of Pai culture. After that, anthropologists (ethnologists) no longer focus on the vertical relations of ancestor worship but on benzhu worship, reflecting the cultural characteristics of the Pai ethnic community. Benzhu worship goes side by side with ancestor worship in Xizhou village. Benzhu is the Pai word for "patrons," which is probably the same thing as "Keng Choo" of Quanzhou (Wang 2003). However, since the 1950s, ethnographers have preferred to associate it with "primitive religion," believing that it is a religion "beyond" the local Pai minority, which unites different Pai villages horizontally into an ethnic community.

To this day, vertical and horizontal connections are still two contexts that social anthropologists cannot ignore when conducting fieldwork. For us, both perspectives have their strengths. The vertical approach allows us to understand better the continuity of the lifestyle and cohesion of the locals within a place. In contrast, the horizontal approach leaves us more room for imagination and enables social anthropological research to go beyond the study of communities. However, living in Xizhou and reading the history of Dali, an anthropologist might imagine something much better than those simply taking these two "approaches" to research. I can vaguely see a historical picture through the flow of time here that reveals an objective history connected by each independent civilization, which over the centuries has gradually been integrated into the "imperial center" and become its "southwestern frontier." I can also vaguely see that this "objective" process of being "marginalized" from the "central" stage has brought a complex feeling to the locals.

On the one hand, to maintain their "central status," they have to defend against marginalization, and on the other hand, to survive in an unequal humanities world, they have to draw on the "civilization" instilled in them from the outside and the top-down. In his doctoral thesis, Liang Yongjia summarized the different reflections of "subjective history" to "objective history" as a "composite culture," which he thought constitutes the Pai people's "indigenous social theory" that features "harmony in diversity.". It seems that, in making such a generalization, an anthropologist is again deducing a third kind of history, namely the anthropological history.

To create an anthropological history, Liang Yongjia focuses on the study of ritual activities centering around Xizhou and divides many types of public rituals other than ancestor worship in Xizhou into native and non-native rituals, arguing that the former are territorial cults while the latter are not. In the context of structural anthropology, Liang believes that the native and non-native rituals constitute a certain composite part of Xizhou because of the principle of the "the unity of opposites between genders" hidden behind them in the local "indigenous social theory." He also borrows from structural anthropology, arguing that this principle implies a hierarchy worthy of attention. This study is therefore defined as a survey of "encompassment." What is "encompassment"? When I visited Liang Yongjia in Xizhou, he told me that in addition to the territorial cults, the people of Xizhou also go on "pilgrimages" to places such as Weibao Mountain (巍宝山) and the Capital of Gods (神都). It is said that the Pai people go there to "receive Jingu (接 金姑).” We later went to this mountain together. I noticed that this mountain is 
one of the most famous Taoist mountains in China, and the "back mountain" is dotted with temples positioned according to feng shui, following the Taoist worldview. The "front mountain" of Weibao Mountain has non-Daoist temples as "pilgrimage" destinations for the Pai people. In other words, the religious pattern of Weibao Mountain is also "pluralistic," representing a "composite culture" without distinguishing "ethnicity." As Liang Yongjia said:

The pilgrimage breaks the distinction between the native and non-native gods in

Xizhou. In the pilgrimage, native and non-native gods with certain important

functions (e.g., fertility, rain) dominate the pilgrimage center. The territorial

cult organizations depend on the native and non-native gods to form a

procession to the pilgrimage site and pray together at the site. The pilgrimage

site boasts temples for native and non-native gods, and the pilgrimage

procession worships both the native and non-native gods. (Liang 2003)

During the presentation on the project, one of the participants asked Liang Yongjia a question: Did the cultural theory of "harmony in diversity" of the Xizhou people come into being after the Ming Dynasty under the influence of Confucianism? He replied that: On the contrary, it was in the process of being "conquered" by Han culture that the Xizhou people developed a cultural vision different from that of the Han, making it possible for them to establish such a cultural theory. This answer moved me. For Chinese anthropology, broadening the horizons of the study from "ethnic minorities" is one of the main tasks of scholars. However, in a country where "Chinese" is the dominant language, how can we reflect on the possible "ethnocentrism" of our writings in anthropological works is a question that needs to be answered in our time. I am pleased with Liang Yongjia's answer, but I must point out that perhaps we have forgotten that such an answer was already reflected in another anthropological study in the era of "Kuige."

\section{Namu Village: exchanges and "Blessings of the Afterlife"}

The piece that attracts me the most among the anthropological writings of the "Kuige" era is Mr. Tien Ju-Kang's description of the research on the "Pai" cult of the Dai people in Mangshi (Capital of the Dehong Dai and Jingpo Autonomous Prefecture). The "Pai" cult is the core religious activity of the Dai people in Dehong. Tien spent 10 months conducting fieldwork in Namu Village of Mangshi around 1940. As one of the young members of "Kuige," Tien once participated in Fei Xiaotong's Sociology Research Office and planned to focus on the economic life of people living in border villages in his fieldwork. During his fieldwork, Tien discovered the importance of the "Pai" cult and realized that the religious ritual, though small in size, is "linked to the entire life of the Dai people" and is "the key to unlocking a vast treasure trove" (Tien 1946). Therefore, he concentrated on studying the "Pai" cult. In 1946, Tien's research was included in the sociology series and published by the Commercial Press in Chongqing. In 1948, he composed his doctoral dissertation, Religious Cults and Social Structure of the Shan States of the Yunnan-Burma Frontier (London School of Economics), revised and published by Cornell University Press in 1986. 
The 1946 Chinese version of Tien Ju-Kang's dissertation, prefaced by Fei Xiaotong, clearly defines the study of the "Pai" cult of Namu Village to explore religious anthropology. Reading the preface and the body of the dissertation, we can find that the research is a religious anthropological study that employs functionalism and integrates different distinctions between religion and magic that Bronislaw Malinowski makes in Magic, Science and Religion and Other Essays (1992) and Émile Durkheim in The Elementary Forms of the Religious Life (1995). In addition, Religious Cults of the Pai-I along the Burma-Yunnan Border gives readers the impression that it was written to draw distinctions between the "Pai" cult and the "non-Pai" cult as well as between religious rituals and supernatural worship rituals. The book devotes one chapter to the conceptual differences between religion and magic, suggesting that these discrepancies explain dissimilarities between "Pai" and "non-Pai" rituals. In short, from Tien's point of view, as a religious ritual, the "Pai" cult possesses the characteristics of non-utilitarianism. During that ritual, people carry out group activities and consume a large amount of money and goods for the sole purpose of "consumption." Like sorcery, the "nonPai" cult, a ritual with utilitarian features, tries to utilize the power of supernatural belief to tackle practical problems in life. Tien did not apply Émile Durkheim's theories of social structure as Fei's preface suggests, nor did he relate the contrasts between the "Pai" cult and the "non-Pai" cult, as well as the disparities between religion and sorcery, to Émile Durkheim's distinctions between society and individual. ${ }^{11}$ Starting from the field observation conducted in Namu Village, Tien linked the utilitarian characteristics of the "non-Pai" cult to social differentiation in the Dai people's daily practices. According to Tien, the "Pai" cult is a religious method for overcoming social differentiation and a system for the Dai people to cover and conquer internal differences.

One of the highlights in Tien's works is the local relationships between "consumption" and "work" that are presented in his ethnographic descriptions (Tien 1946). For the Dai people, "work" is a means to accumulate wealth. Unlike societies adopting modern economic models, however, the Dai society's wealth accumulation does not strive to create class status differences among people through "expanding reproduction." Instead, the Dai people accumulate wealth to balance the discrepancies among people from different social classes through the "consumption" of religious rituals. The "Pai" cult expending enormous wealth can achieve the goal of eliminating dissimilarities of social and economic status between individuals by "wasting" the wealth amassed by "work," thus achieving social integration. That is to say, the ritual of the "Pai" cult, as a "balance mechanism," emphasizes the one-way devotion of people to gods and Buddhas. People expect to increase "merits" for their afterlife through devotion and achieving the desired good "karma." The logic of "karma" shows the Dai people's religious reflections on the structure of the hierarchical society to which they belong. The prerequisite for the existence of the Dai society is "a pious psychology and a

\footnotetext{
${ }^{11}$ According to Émile Durkheim, religion is collective and transcendent, while magic is individual and "technical."
} 
serious attitude" that enables the people not to yield to real social differences so that they can form a community.

Tien's research is quite appealing because he developed the theory of discovering from "alien cultures" the "market" concept system that is going mainstream. I always believe that Tien's research not only expands the cultural vision of the "leisure economy" concept proposed by Fei Xiaotong in his research on Lu Village but also indicates in a modest mode of expression that the study of alien "border people" cultures can open up a cross-cultural dialogue space for the research of the Han people's native culture. With this expectation in mind, I asked Chu Jianfang to determine his position in this space when I directed his doctoral dissertation. Chu Jianfang began his fieldwork in Namu Village in March 2002 and completed the survey within 7 months. A "re-study" requires us to add some new findings to previous achievements. Chu Jianfang went to Namu Village with this target in mind. On May 13, 2002, I paid a visit to him in the village, during which I advised him to center the idea that Tien had implicitly expressed about making anthropological, cultural criticism in different social forms. I also suggested that he describe, from a social anthropological perspective, the coexistence, contradiction, and integration of the emerging "cultural hierarchy," with a school as the core modern social ecology and the "hierarchy" of the Dai people's "local knowledge" fixed in a specific location. With its rational approach, Chu Jianfang's final research expresses his views on the internal social logic of the "Pai" cult.

Chu Jianfang focused on the same "Pai" cult as Tien Ju-Kang in his doctoral dissertation. In opposition to Tien, Chu upheld that Tien "only stresses the almsgiving and wealth distribution by the local Dai people" and "is not concerned about 'obtaining' and 'accumulating"" (Chu 2003). In order to supplement the aspect of "obtaining" and "accumulating," Chu Jianfang established his research framework, arguing that the relationship between "humans" and "god" cannot be summarized as a one-way "devotion." However, there should be a certain type of "exchange relationship" between the two. In other words, the Dai people perform the "Pai" cult not only out of "piety," but they also have a mentality of expecting something in return. The ritual of the "Pai" cult pursues the "exchange" of "merits" between humans and god, for the sake of positions that humans can attain in the afterlife. With that said, it seems that in Chu Jianfang's analysis, the "Pai" cult, like the "non-Pai" cult, has a utilitarian nature, rather than just an expression of "devout psychology." The "social function" of the "Pai" cult, which is a way for a "society full of hierarchies" to strengthen its own classes, is not to balance social class differences through "consumption" but to highlight the equivalence between discrepancies of "merit" and "karma."

Chu Jianfang also used the concept of "reciprocity" to express his understanding of the "human-god exchange," aiming to explain that hierarchical differences between humans and god are not "undesirable." When applying the concept of "reciprocity," Chu also recognized Tien's spirit of seeking "cultural criticism" from different cultures. However, associating the hierarchical spirit of rituals with the hierarchical characteristics of a real society creates the impression of "universalist hierarchical theory," thus "consuming" within the case study the strength of Tien's conviction for cross-cultural dialogue that boasts several relativist features. We 
should also note that if we deny Tien's "functionalism," we risk taking religion and sorcery as "utilitarian" pursuits and may forget a historical fact worthy of "remembering." That is, the "Pai" cult and the "non-Pai" cult in Tien's theories are the foreign religion (Buddhism) and the local "religion" (supernatural belief) that the Dai people absorb. Tien's comparative analysis of the non-utilitarian "Pai" cult (Buddhist rituals done by the Dai people) and the utilitarian "non-Pai" cult (local supernatural beliefs and rituals) can be explained by returning to the historical process in which Theravada Buddhism in Southwest China functions as a "cultural connection structure" between "orthodoxy" and "indigenous religion" (Sahlins 2003). This "re-study" background should be the integration of historical anthropology. The "connection" between "new orthodoxy" and "old orthodoxy" that is caused by social changes since the 1940s should be the focus of the "re-study." To me, this simply means that the "re-study" of Namu Village should not be separated from the "re-study" of other fieldwork sites in Yunnan Province, just as it should not be detached from the academic history of "Kuige."

\section{Conclusion: reexamination on "human ecology"}

It seems that the young generation of Chinese anthropological researchers is entangled with the traditional "purely descriptive" ethnography and the abstract theory of "postmodernism" to the point that they now "face a dilemma." Scholars are interested in the achievements accumulated in the 1930s, 40s, and 50s, but few are determined to establish an academic relationship between those achievements and our research. In this context, Zhang Hongming, Liang Yongjia, and Chu Jianfang entered social anthropology from different disciplines. Before being admitted to the Ph.D. program, the three students only read and translated a few pieces from the anthropological canons. Over the years, their academic enthusiasm was often dampened. Besides, considering the objective conditions, it is not easy for me or them to carry out independent research based on inheritance. Therefore, it is natural that there are many questions in their research and dissertations.

I have visited all their fieldwork sites. Although what I saw may have only been a few glimpses due to the short time, I am satisfied with the communication and reciprocal relationships formed with them during my visits. I learned much from all the new information I gained and felt rare encouragement from their sincerity. It was gratifying to see that, in their "re-studies" of Fei Xiaotong's research of Lu Village, Francis L. K. Hsu's research of "Xizhen" (Xizhou Town), and Tien JuKang's research of Namu Village, that the students' dissertations all demonstrated the will to inherit the accomplishments of the three predecessors of Chinese anthropology. It is also pleasing that the three students did not forget to open new horizons on this will to inherit past accomplishments. To varying degrees, their dissertations present reflections with different profiles. From these examples of "reflective inheritance," social anthropologists who have been confronted with numerous challenges for many years can now see the possibility of creating an academic language community. 
What is not stated is that the three Ph.D. dissertations are inseparable from the "human ecology" tradition of the Chinese social sciences. This tradition of "human ecology" that emerged in the 1930s is closely related to Robert Park, a Chicago school sociologist from the US, and A.R. Radcliffe-Brown, an English social anthropologist who developed the theory of structural functionalism, who visited Yenching University to deliver lectures in 1932 and 1935 respectively. The basic methodology of "human ecology" comes from ecology. Therefore, "human ecology" can be defined as social anthropological research that looks at the processes in which a human community adapts to a larger social environment. Initially, this methodology was influenced by biology and differed from the structuralfunctionalism of social anthropology. However, the meaningful association between the methodology and structural functionalism was obtained in the discussions that mainly took place in Yenching University more than 70 years ago (Zhao 2002 [1933]). When giving lectures at the university, Radcliffe-Brown, a master of structural functionalism, abandoned the previous practice of advocating structural research and proposed the idea of conducting community surveys on Chinese villages, even claiming that "the most suitable unit for research in China is the village (community)" (Radcliffe-Brown 2002 [1936]). Apart from the close relationships between the Chicago school of sociology and British social anthropology, Wu Wenzao, who invited Park and Brown to present lectures in China, together with his colleagues and students, are the "local force" promoting the integration between the community surveys of sociology and the ethnographic research of social anthropology. Fei Xiaotong, Francis L. K. Hsu, and Tien Ju-Kang, the predecessors of Chinese social anthropology, are also members of this force.

These three predecessors have their own academic research focus. Fei Xiaotong paid particular attention to the study of land issues, Francis L. K. Hsu, who was deeply influenced by cultural anthropology in the US, valued the study of the accepted customs and rules of conduct, and Tien Ju-Kang was concerned with the inspiration of the lifestyle of "border people" to the "mainstream society." Among the three scholars, Fei and Hsu desired to gain insights into Chinese society through the research of small places. Fei adopted the method of type comparison, while Hsu regarded small places as "miniatures." Only Tien was more interested in the issue of the "other" in social anthropology, and he tried to obtain insights from community surveys on "border people" to reflect on ritual forms of mainstream models from the market economy. They all realized the important positions held by public rituals in the villages, and they studied the social forms presented by rituals as "pre-capitalist" cultures. The differences are that Fei hoped to discover the course of modernization from his research, and Hsu deemed that the social lifestyle of "one large family" expressed by family rituals is a model that differed from that of the modern nuclear family and supplemented its psychological regrets. Tien maintained that public rituals conveyed rare piety and an internal reflection on a hierarchical society.

For our predecessors, "human ecology" is a methodology and a spirit of field research that broadens the horizons for different interpretations. In my own research, I do not doubt the new meaning of this old methodology. My research of urban and rural communities is also inspired by "human ecology." Although I did not 
elaborate on the meaning of "human ecology," I have indirectly pointed out the questionable aspects of this methodology in reflections on ethnographic methods. In my opinion, the "human ecology," enlightened as it is by biology, contains an "ecological theory," which provides us with an approach to grasping the community from the "objective adaptation process." However, the deficiency of "human ecology" is that it fails to fully grasp the "conditions" offered by the larger scope of existence in such locations when it focuses on "small places" that serve as humanistic locations. Although Maurice Freedman, an expert on Chinese anthropology, provides a valuable way of thinking for us to understand such conditions, I prefer to stick to the methodology of "human ecology" as well as to explicitly apply the achievements of sociologists who have studied how societies are constituted and the accomplishments of historians (including ethnohistorians) who have examined relatively large historical processes (Wang 1997a, b).

It should also be noted that for many years I have devoted efforts to the examination of public rituals. Entering society from public rituals is possible for anthropologists to study "human ecology" with historical significance. Fei Xiaotong has already explained the reasons for this from the perspective of the distribution of time in the Farmland of Lu Village. Fei was concerned about the model of the economic life of a "pre-modern agricultural society." He argued that, unlike capitalist societies, peasant societies have plenty of "leisure time," which is spent on consumptive ("wasteful") rituals rather than on increasing the value of labor. He wrote that:

Reducing labor and consumption gives rise to leisure. In a city, people are busy with their work and enjoy the entire day; they cannot relax during the socalled rest days and usually become tired as they take entertainment as a serious matter. It seems that they cannot gain pleasure without spending money. However, the situation is just the opposite in rural China. Peasants know the method to get pleasure without the cost of pain. That is called leisure. The difference between leisure and consumption is that the latter is a process of obtaining pleasure by consuming materials, while the former only consumes some idle time instead of materials (Fei et al. 1990).

According to Fei Xiaotong, from the public rituals in which farmers (including ethnic minority farmers) immerse themselves, anthropologists can discover that "leisure time" plays a role in providing a cultural foundation for the relatively low production value and low capital accumulation of agricultural communities. This cultural basis for the Chinese agricultural society may gradually collapse due to the development of industry and commerce. In other words, anthropologists can comprehend the models used by that society to maintain its order of relations through the research of public rituals. In doing so, they can identify the pressure the society faced during modernization and understand the historical issues brought about by the traditional Chinese society's transition to a modern one.

It is interesting to notice that understanding the internal characteristics of China's domestic "marginal traditions" through public rituals seems to be the common pursuit of the three predecessors of Chinese anthropology. When dealing with the historicity of public rituals, the three predecessors, who were enormously influenced by Bronislaw Malinowski's theory of culture, Radcliffe-Brown's comparative sociology, and Ralph Linton's psychological anthropology, adopted an attitude that features the "pragmatism" of the theory 
of culture and implies potential historical reflections on the modernization process. Tien Ju-Kang rethought Fei Xiaotong's interpretation of ritual time during the "Kuige" period. ${ }^{12}$ Tien valued the common issue in a private ownership society: the inequality of private properties. He contended that public ritual is indeed the key approach of what Fei Xiaotong calls "consumption." However, this method helps construct the "transcendence" of religions, and it offers a means for societies to overcome conflicts provoked by private property. Tien said, "This method is an approach in which the Pai-I society utilizes the 'Pai' cult to accelerate consumption. It creates a security mechanism for the private property system so that what is excessively taken from the society is finally returned to the society" (Tien 1946). Coincidentally, we can observe from Francis L. K. Hsu's works how ancestor worship activities held over a long time have generated a relatively stable lifestyle that is inherently different from modern society's sense of time-fractured history. One of the concerns of Hsu's academic life was the cultural limitations of Western individualism. He maintained that public rituals of the family produced a blood-based collective that provides an essential basis for advancing the anthropological research of Western individualism (Hsu 1990).

Due to the limitations of their period, these discussions made by the three predecessors of anthropology were all based on Durkheim's "temporal metaphysics," which would be taken by the researchers" "social rationality" as the fundamental reason to explain their temporal system. As Alfred Gell has pointed out, the consequences will be to describe farmers as a group of "backward-looking creatures" regarding time, and then indicate how intellectuals are "forward-looking" regarding time in the process of urbanization through the metaphysical imagination of farmers' "social rationality" (Gell 1992). Moreover, their ethnographic writing only relates to history in a metaphorical way, which can be very general when it comes to the history of their studied sites. All three studies of the "Kuige" period have represented a snapshot of their times by public rituals, a tradition of cultural relations passed down from generation to generation through the stipulation of the annual cycle in the community and the arrangement of the life cycle. However, the three studies focused too much on discussing "synchronic" problems in community studies, resulting in a neglect of the "mode of production" and a change of role for the local tradition of cultural relations over time. At the same time, all three studies paid too much attention to the "objective existence" of "social facts" but somewhat made light of the subjective will of "historical sense" and "sense of place" that are embodied in public rituals. In some ways, the Social-history Surveys of China's Ethnic Minorities since the 1950s have, perhaps, added abundant regional and ethnic history materials to "human ecology" at an important level. However, due to the prevailing "social formation theory" at that time, these studies did not have a sufficient "sense of place."13

\footnotetext{
${ }^{12} \mathrm{Fei}$ also made a substantial contribution to Tien's reexamination. It should not be forgotten that Fei gave a title for Tien's book and produced the mimeographed version of Tien's first work.

${ }^{13}$ In the long run, it is when they are incorporated into new historical, anthropological studies and combined with the solid fieldwork that emerged in the 1930s and 1940s that they are likely to produce exciting achievements to facilitate our understanding of traditions, the objective course of history, and the subjective perception of history.
} 
The three doctoral dissertations completed at the beginning of the twenty-first century, which narrate as a type of "re-study," have put forward discussions on the history and social structure of public rituals in villages of the Han, Pai and Dai from different perspectives, and have also made interpretations on the history of public rituals in varying depth and breadth. These interpretations are original and admirable in many aspects. As a Chinese saying goes, "A junzi (Man of Virtue) seeks harmony but not uniformity." Although the three studies took different paths and came to different conclusions, when they are taken together, and they inspire us in the same way. What exactly do they inspire? Owing to the lack of in-depth discussion among the three, this question remains to be explored in the future. In order to fulfill what is required of me as an educator and to advocate the spirit of "learning and constantly reviewing what one has learned," I will try my best to explore the untapped potential in students' research. The above discussions about the relationship between time and "social rationality" and the relationship between history and reality, are the two areas with more room for exploration in my eyes. Personally, I am convinced that conducting dialogues around these two areas will help advance all three studies. Moreover, from a broader view, higher expectations from me should be: the future re-studies still need to broaden the historical imagination and explanatory power of anthropology upon the foundation of solid fieldwork, and carry out sufficient research in terms of timescale on the "structure" of the relationship between the center and the periphery in different eras, so as to make due contributions to the comprehension of "Chinese society."

Acknowledgements Not applicable.

Author's contributions Individual authorship. The author read and approved the final manuscript.

Funding Not applicable.

Availability of data and materials Not Applicable.

\section{Declarations}

Ethics approval and consent to participate Not applicable.

Consent for publication I accept the copyright regulation of your journal and authorize your journal to publish my paper, if possible.

Competing interests The author has no conflict of interest.

Open Access This article is licensed under a Creative Commons Attribution 4.0 International License, which permits use, sharing, adaptation, distribution and reproduction in any medium or format, as long as you give appropriate credit to the original author(s) and the source, provide a link to the Creative Commons licence, and indicate if changes were made. The images or other third party material in this article are included in the article's Creative Commons licence, unless indicated otherwise in a credit line to the material. If material is not included in the article's Creative Commons licence and your intended use is not permitted by statutory regulation or exceeds the permitted use, you will need to obtain permission directly from the copyright holder. To view a copy of this licence, visit http:// creativecommons.org/licenses/by/4.0/. 


\section{References}

A. R. Radcliffe-Brown, 2002 [1936]. "Suggestions for the investigation of sociology of rural life in China" (对于中国乡村生活社会学调查的建议), collected in community and function - Park \& Brown's sociological collected works and notes (《社区与功能——派克、布朗社会学文集及学记》), Peking University Press (北京大学出版社).

Bossen, Laurel. 2002. Chinese women and rural development: Sixty years of change in Lu Village, Yunnan. Oxford: Rowman and Littlefield Publishing, Inc..

Bronislaw, Malinowski. 1992. Magic, science and religion and other essays. Waveland Pr Inc..

Chu, Jianfang (禇建芳), 2003. Between People and Gods: The Ritual Life, Economic Ethics and Hierarchical Order of a Dai Village in Mangshi, Yunnan (《人神之间——云南芒市一个傣族村寨的仪式生活、经 济伦理与等级秩序》), Beijing: Doctoral Dissertation at Peking University (北京大学博士学位论文).

Durkheim, Emile. 1995. The elementary forms of the religious life. Free Press.

Fei, Xiaotong (费孝通), 1998. Conversations on How to Learn from Facts (《从实求知录》), Beijing: Peking University Press (北京大学出版社).

Fei, Xiaotong (费孝通), 1993. The study of Man in China (《人的研究在中国》), Tianjin: Tianjin People's Publishing House (天津人民出版社).

Fei, Xiaotong et al.(费孝通等), 1990. Three villages in Yunnan (《云南三村》), Tianjin: Tianjin People's Publishing House (天津人民出版社).

Freedman, Maurice. 1963. A Chinese phase in social anthropology. British Journal of Sociology 14 (1): 119. https://doi.org/10.2307/587316.

Freeman, Derek, translated by Li Chuanjia (李传家译), 1990. Margaret Mead and Samoa (《玛格丽特. 米德 与萨摩亚》), Bejing: Guangming Daily Press (光明日报出版社).

Gell, Alfred. 1992. The anthropology of time: Cultural constructions of temporal maps and images. Oxford: Berg.

Hsu, Francis L.K. 1948. Under the Ancestors' shadow: Chinese culture and personality. New York: Columbia University Press. https://doi.org/10.7312/hsu-94494.

Hsu, Francis L.K. 1990. My life as a marginal man. Taipei: National Institute for Compilation and Translation, SMC Publishing Inc..

Liang, Yongjia (梁永佳), 2003. Hierarchical Structure of Regional Worship -- A Field Study of Ritual and Culture in Xizhou Town of Dali (《地域崇拜的等级结构一一大理喜洲仪式与文化的田野考察》), Beijing: Doctoral Dissertation in Peking University (北京大学博士学位论文).

Pan, Naigu (潘乃谷), 2001. “Province University Cooperation Project and Sociological Anthropology Research in Yunnan during the Anti-Japanese War”(抗战时期云南的省校合作与社会学人类学研究), Yunnan: Journal of Yunnan Minzu College (《云南民族学院学报》), 2001:5.

Sahlins, Marshall (马歇尔·萨林斯), 2003. How “natives” think: About captain cook, for example (《"土 著"如何思考——以库克船长为例》), Shanghai: Shanghai People's Publishing House (上海人民出版 社).

Sangren, P. Steven. 1987. History and magical power in a Chinese community. Stanford: Stanford Univerity Press.

Tien, Ju-kang (田汝康), 1946. Religious cults of the Pai-I along the Burma-Yunnan border (《芒市边民的 摆》), Chongqing: Chongqing Commercial Press (重庆商务印书馆).

Wang, Jianmin (王建民), 1997a. History of Chinese Ethnology - Vol. 1 (《中国民族学史》(上卷)), Yunnan: Yunnan Education Publishing House (云南教育出版社).

Wang, Mingming (王铭铭), 1997b. Social anthropology and sinology (《社会人类学与中国研究》), Beijing: SDX Joint Publishing Company (北京三联书店).

Wang, Mingming (王铭铭), 1999. Prosperity that has gone by: A historical anthropology of an Old City (《逝去 的繁荣——座老城的历史人类学考察》), Zhejiang: Zhejiang People's Publishing House (浙江人民出 版社).

Wang, Mingming (王铭铭), 2003. Beyond Rural China - Notes on Historical Anthropology (《走在乡土 上一一史人类学札记》), Beijing: China Renmin University Press (中国人民大学出版社).

Wang, Mingming (王铭铭), A Traveler of Kuige (魁阁的过客), Beijing: Dushu (《读书》), Vol. 2, 2004 .

Wang, Mingming (王铭铭), 1998. Culture and power from the perspective of village (《村落视野中的文化 与权力》), Beijing: SDX Joint Publishing Company (北京三联书店).

Xie, Yong (谢泳), 1998. Kuige - “The Prototype of China Modern Academic Group” (魁阁——中国现代 学术集团的雏形), collected in Southwest Associated University and Chinese Modern Intellectuals (《西 南联大与中国现代知识分子》), Hunan: Hunan Literature and Art Publishing House (湖南文艺出版社). 
Zhang, Guansheng (张冠生), 2000. Biography of Fei Xiaotong (《费孝通传》), Beijing: Qunyan Press (群言 出版社).

Zhang, Hongming (张宏明), 2002. The Change of Land System and Public Rituals - The Restudy of Lu Village (《土地制度与公共仪式的变迁——禄村再研究》), Beijing: Doctoral Dissertation in Peking University (北京大学博士学位论文).

Zhao, Chengxin, 2002 [1933]. "Parker and Human ecology" (派克与人文区位学), collected in community and function - Park \& Brown's sociological collected works and notes (《社区与功能——派克、布朗 社会学文集及学记》), Beijing: Peking University press (北京大学出版社).

Zhuang, Kongshao (庄孔韶), 2000. The silver wings (《银翅》), Beijing: SDX Joint Publishing Company (北 京三联书店).

\section{Comments}

Publisher's Note Springer Nature remains neutral with regard to jurisdictional claims in published maps and institutional affiliations. 